\title{
ВЛИЯНИЕ СПОСОБА СМЕШЕНИЯ НА СТРУКТУРУ И СВОЙСТВА СМЕСЕЙ НА ОСНОВЕ ПОЛИЭТИЛЕНА И СОПОЛИМЕРОВ ЭТИЛЕНА
}

\author{
Р. М. Хузаханов, А.Н. Ибатуллин, И.Ш. Хабриев, В.Ф. Хайрутдинов, \\ Ф. М. Гумеров, А.Р. Хузаханов, Р.М. Гарипов
}

\begin{abstract}
РАФАИЛЬ МУХАМЕТСУЛТАНОВИЧ ХУЗАХАНОВ - д.т.н., профессор кафедры «Химии и технологии пе-
\end{abstract} реработки эластомеров», ФГБОУ ВО КНИТУ. E-mail: huzahanov62@mail.ru.

АЗАТ НАФИСОВИЧ ИБАТУЛЛИН - аспирант кафедры «Химии и технологии переработки эластомеров», ФГБОУ ВО КНИТУ. E mail: azat.ibatullin.1996@mail.ru.

ИЛЬНАР ШАМИЛЕВИЧ ХАБРИЕВ - к.т.н., стариий лаборант кафедры «Теоретических основ теплотехники», ФГБОУ ВО КНИТУ.Е mail: termi0@yandex.ru.

ВЕНЕР ФАИЛЕВИЧ ХАЙРУТДИНОВ - д.т.н., доиент кафедры «Теоретических основ теплотехники», ФГБОУВО КНИТУ. Е mail: kvener@yandex.ru.

ФАРИД МУХАМЕДОВИЧ ГУМЕРОВ - д.т.н., заведующий кафедрой «Теоретических основ теплотехники», ФГБОУВО КНИТУ. E-mail: gum@kstu.ru.

АНВАР РАФАИЛЕВИЧ ХУЗАХАНОВ - магистрант кафедры «Технологии пластических масс», ФГБОУ ВО КНИТУ. E-mail: a.huzahanov98@yandex.ru.

РУСЛАН МИРСАЕТОВИЧ ГАРИПОВ - д.т.н., заведующий кафедрой «Технологии полиграфических проиессов и кинофотоматериалов», ФГБОУ ВО КНИТУ. E-mail: rugaripov@mail.ru.

420015, г. Казань, ул. Карла Маркса д. 68, ФГБОУ ВО «Казанский наџиональный исследовательский технологический университет», Россия.

В работе представлены результаты смешения и диспергирования бинарных смесей СЭВА (сополимер этилена с винилацетатом) и смесей с полиэтиленом, осуществленного с использованием метода антирастворителя (SEDS). Исследованы кинетики плавления и кристаллизации в смесях полимеров, полученных смешением в расплаве и с использованием метода SEDS. Методами рентгенографии и ДСК установлено, что кристаллизачия смесей полимеров методом SEDS приводит к увеличению степени кристалличности. Приведены результаты исследования физико-механических характеристик исследуемых смесей.

Ключевые слова: сверхкритический флюидный антирастворитель, сверхкритический диоксид углерода, сополимеры этилена с винилацетатом, полиэтилен. 


\title{
INFLUENCE OF THE MIXING METHOD ON THE STRUCTURE AND PROPERTIES OF BLENDS BASED ON POLYETHYLENE AND COPOLYMERS OF ETHYLENE
}

\author{
R. M. Khuzakhanov, A. N. Ibatullin, I.Sh. Khabriev, V. F. Khairutdinov, \\ F.M. Gumerov, A.R. Khuzakhanov, R.M. Garipov
}

68 Karl Marx str., Kazan, 420015, Russia. Kazan National Research Technological University.

The paper presents the results of mixing and dispersing binary mixtures of EVA (ethylene vinyl acetate copolymer) and mixtures with polyethylene, carried out using the anti-solvent method (SEDS). The melting and crystallization kinetics in polymer blends obtained by mixing in a melt and using the SEDS method have been investigated. It was found by X-ray diffraction and differential scanning calorimetry (DSC) methods that the crystallization of polymer blends by the SEDS method leads to an increase in the degree of crystallinity. The results of the study of the physical and mechanical characteristics of the mixtures under study are presented.

Key words: supercritical fluid anti-solvent, supercritical carbon dioxide, ethylene vinyl acetate copolymer, polyethylene.

\section{Введение}

Смешение полимеров является одним из распространенных способов создания новых композиционных материалов с необходимым комплексом свойств. Как правило, основным методом получения смесей полимеров является смешение в расплаве [1-3]. Однако в настоящее время все более широко используются не традиционные технологии, в частности применение суб- и сверхкритических флюидных сред и, прежде всего, сверхкритического диоксида углерода, являющимся также экологически безопасным способом [4-7].

Ранее в работах $[8,9]$ были показаны необычные физико-химические свойства смесей сополимеров этилена с винилацетатом (СЭВА) с различным содержанием винилацетатных звеньев (BA), выражающееся в повышении степени кристалличности и модуля упругости. Следует отметить, что в этих работах все изученные смеси были получены смешением в расплаве, поэтому представ- ляло интерес изучение этих же объектов, полученных при смешении в среде сверхкритического диоксида углерода с использованием метода SEDS. Некоторые исследования были проведены в работе [10]. Продолжение изучения этих систем и было осуществлено в данной работе.

\section{Экспериментальная часть}

В качестве объектов исследований использованы следующие полимеры и сополимеры: полиэтилен высокого давления марки 15303-003 (ПЭВД), сополимеры этилена с винилацетатом с различным содержанием ВА марок СЭВА - 11306-075, СЭВА 11507-375, СЭВА 11808-1750. Некоторые свойства полимеров показаны в табл. 1.

Сверхкритическим флюидным антирастворителем в процессе смешения был использован диоксид углерода с чистотой 99,0 \% (ГОСТ 8050-85). В качестве растворителя использовали толуол марки «Х.ч.» (ТУ 2631-065).

Характеристики исследуемых полимеров

\begin{tabular}{clcccc}
\hline \multirow{2}{*}{ № } & \multicolumn{1}{c}{ Характеристики } & $\begin{array}{c}\text { ПЭВД } \\
\mathbf{1 5 3 0 3 - 0 0 3}\end{array}$ & $\begin{array}{c}\text { СЭВА } \\
\mathbf{1 1 3 0 6 - 0 7 5}\end{array}$ & $\begin{array}{c}\text { СЭВА } \\
\mathbf{1 1 5 0 7 - 3 7 5}\end{array}$ & $\begin{array}{c}\text { CЭВА } \\
\mathbf{1 1 8 0 8 - 1 7 5 0}\end{array}$ \\
\hline 1 & Содержание винилацетатных групп, \% & - & 14 & 20 & 29 \\
2 & Температура плавления $\mathrm{T}_{\text {пл }}{ }^{\circ} \mathrm{C}$ & 108 & 99 & 82 & 75 \\
3 & Степень кристалличности, $\%$ & 35,6 & 16,6 & 8,9 & 5,3 \\
4 & Теплота плавления $\mathrm{Q}_{\text {пл. }}$, Дж/г & 72,1 & 43,1 & 17,6 & 8,7 \\
\hline
\end{tabular}




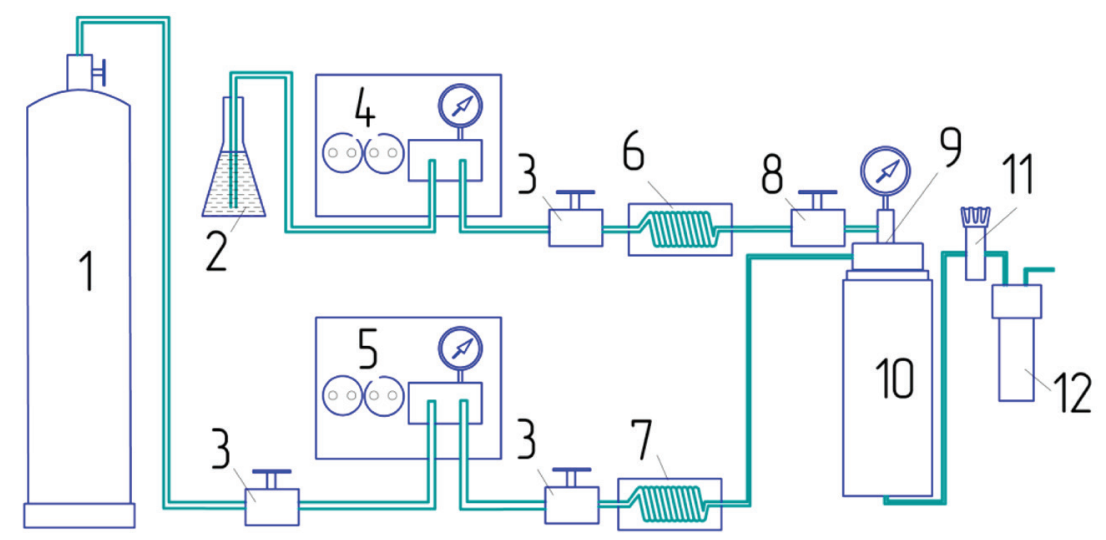

Рис. 1. Схема экспериментальной установки для диспергирования смесей полимеров по методу SEDS

1 - баллон с $\mathrm{CO}_{2}, 2$ - емкость для раствора «исследуемое вещество - органический растворитель», 3 - вентиль, 4 - насос подачи раствора, 5 - насос подачи $\mathrm{CO}_{2}, 6$ - нагреватель раствора, 7 - нагреватель $\mathrm{CO}_{2}$,

8 - вентиль на линии подачи раствора в сопло, 9 - коаксиальное сопло, 10 -реактор, 11 - регулятор обратного давления, 12 - сепаратор

Принципиальная схема экспериментальной установки, предназначенной для смешения и диспергирования смесей полимеров по методу SEDS, представлена на рисунке 1.

Лабораторная установка состоит из системы создания, регулирования и измерения давления, системы измерения и регулирования температуры, систем подачи раствора смеси полимеров в органическом растворителе и антирастворителя, ячейки осаждения и системы сбора частиц.

Подача растворов смесей полимеров в органическом растворителе (2) и $\mathrm{CO}_{2}$ (1) осуществляется плунжерными насосами фирмы THAR (CША) $(4,5)$. Цилиндрическая емкость из нержавеющей стали объемом 1 литр используется в качестве ячейки осаждения (10). Давление в ячейке измеряется с помощью манометра и регулируется регулятором обратного давления (11). Впрыскивание жидкого раствора и подача сверхкритического диоксида углерода происходят одновременно через коаксиальное сопло (9). При этом, раствор полимеров в органическом растворителе подается по внутреннему отверстию, а сверхкритический $\mathrm{CO}_{2}$ по внешнему кольцевому зазору. Для сбора частиц на дне реактора устанавливается металлическая подложка. Оставшийся после эксперимента органический растворитель собирается в сепараторе (12) для повторного использования.

Композиции, полученные смешением в расплаве, готовили в смесительной камере «Measuring Mixer 350Е» смесительного оборудования фирмы Brabender «Plasti - Corder ${ }^{\circledR}$ Lab-Station» (Германия).

Образцы для испытаний получали прессованием на гидравлическом прессе марки YT-30RS по методике описанной в работе [9]. Деформаци- онно-прочностные свойства образцов определяли по ГОСТ 11262-76 на разрывной машине TeST $\mathrm{GmbH}$ модель $112.5 \mathrm{kN}$ при скорости 50 мм/мин.

Исследование кинетики кристаллизации и превращение фаз в смесях полимеров проводили с помощью дифференциального сканирующего калориметра (ДСК) Perkin-Elmer DSC 7 с программным обеспечением Pyris. Скорости нагрева и охлаждения составляли $10{ }^{\circ} \mathrm{C} / \mathrm{Mин}$.

\section{Результаты и обсуждение}

При изучении процессов плавления и кристаллизации смесей СЭВА с использованием метода дифференциальной сканирующей калориметрии, выполненных ранее в работе [10] было обнаружено, что для всех полимерных смесей, полученных смешением и диспергированием по методу SEDS, в отличие от смешения в расплаве, реализуется система с повышенной степенью структурной упорядоченности, выраженной возрастанием удельной теплоты плавления и соответственно степени кристалличности по сравнению с аддитивными значениями. Диаграммы одной из смесей показаны на рисунке 2.

Результаты всех исследований объединены в таблицу 2.

Необходимо отметить, что в смеси СЭВА113 (30 \%)-СЭВА115 (70\%), полученной смешением в ксилоле теплота плавления составила 22,4 Дж/г, которая также ниже теплоты плавления смеси, полученной смешением по методу SEDS.

Для подтверждения увеличения степени кристалличности смесей были проведены рентгеноструктурные исследования. Были проанализиро- 

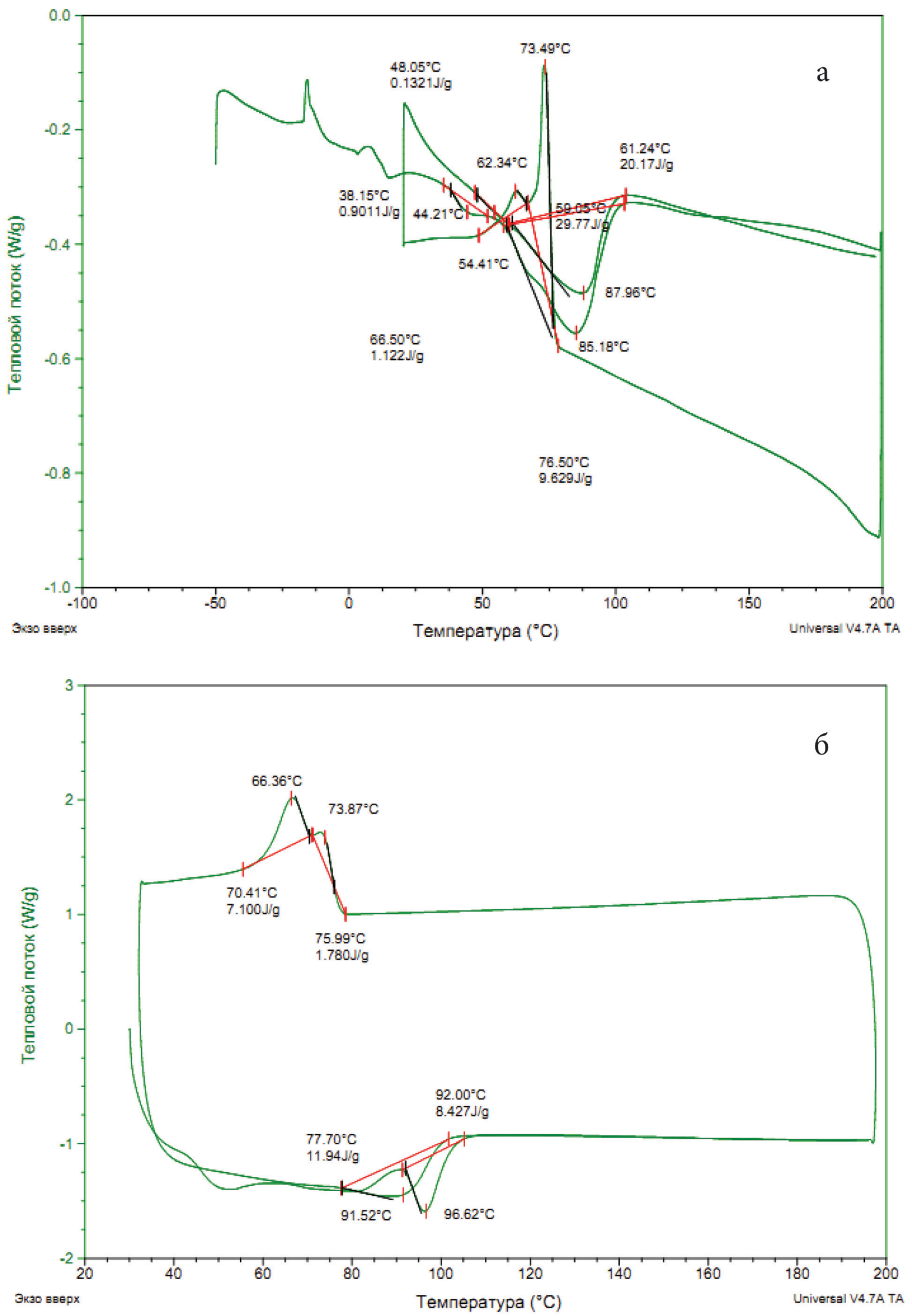

Рис. 2. Кривые ДСК смесей СЭВА113 (30 \%) - СЭВА115 (70 \%), полученных смешением по методу SEDS (а) и смешением в расплаве (б) 
Температура и теплота плавления смесей полимеров полученных методом ДСК

\begin{tabular}{|c|c|c|c|c|}
\hline \multirow[b]{2}{*}{ Состав смеси } & \multicolumn{2}{|c|}{ Смешение в расплаве } & \multicolumn{2}{|c|}{ Смешение по методу SEDS } \\
\hline & $\mathbf{T}_{\text {пл. }}{ }^{\circ} \mathbf{C}$ & $\begin{array}{c}\text { Суммарное } \\
\mathbf{Q}_{\text {пл. }} \text { Дж/г }\end{array}$ & $\mathbf{T}_{\text {пл. }}{ }^{\circ} \mathbf{C}$ & $\begin{array}{c}\text { Суммарное } \\
\mathbf{Q}_{\text {пл. }} \text { Дж/г }\end{array}$ \\
\hline $\begin{array}{l}\text { CЭВА-113 (30 \%) } \\
\text { СЭВА-115 (70 \%) }\end{array}$ & $\begin{array}{c}96,62 \\
82 \text { (два пика) }\end{array}$ & 11,94 & 85,18 (один пик) & 29,77 \\
\hline $\begin{array}{l}\text { СЭВА-113 (70 \%) } \\
\text { СЭВА-115 (30 \%) }\end{array}$ & $\begin{array}{c}96,89 \\
78,57 \text { (два пика) }\end{array}$ & 25 & 90,1 (один пик) & 30,3 \\
\hline $\begin{array}{l}\text { CЭBA-113 (50 \%) } \\
\text { CЭВА-118 (50 \%) }\end{array}$ & $\begin{array}{c}92,61 \\
71,25 \text { (два пика) }\end{array}$ & 16,25 & $\begin{array}{c}90,11 \\
66,1 \text { (два пика) }\end{array}$ & 19,93 \\
\hline $\begin{array}{l}\text { ПЭВД-153 (50 \%) } \\
\text { СЭВА-118 (50 \%) }\end{array}$ & $\begin{array}{c}106,51 \\
73,63 \text { (два пика) }\end{array}$ & 24,72 & $\begin{array}{c}98,35 \\
69,43 \text { (два пика) }\end{array}$ & 50,6 \\
\hline
\end{tabular}

ваны смеси, полученные при смешении по методу SEDS и показавшие наибольшую теплоту плавления.

Исследования проведены на порошковом дифрактометре XRD-7000S, материал мишени - $\mathrm{Cu}$ $(\lambda=1,54 \mathrm{~A})$, рабочий ток $-30 \mathrm{MA}$, рабочее напряжение - 30 кВ; пошаговый режим сканирования, шаг $-0,05^{\circ}$, время экспозиции -5 с. Съемка образцов осуществлялась при комнатной температуре, предобработка образцов не проводилась.

Результаты исследований представлены на рисунках 3-7, в которых сперва приводится значение степени кристалличности образца, рассчитанное в программе TOPAS V4.2, затем значение, рассчи-

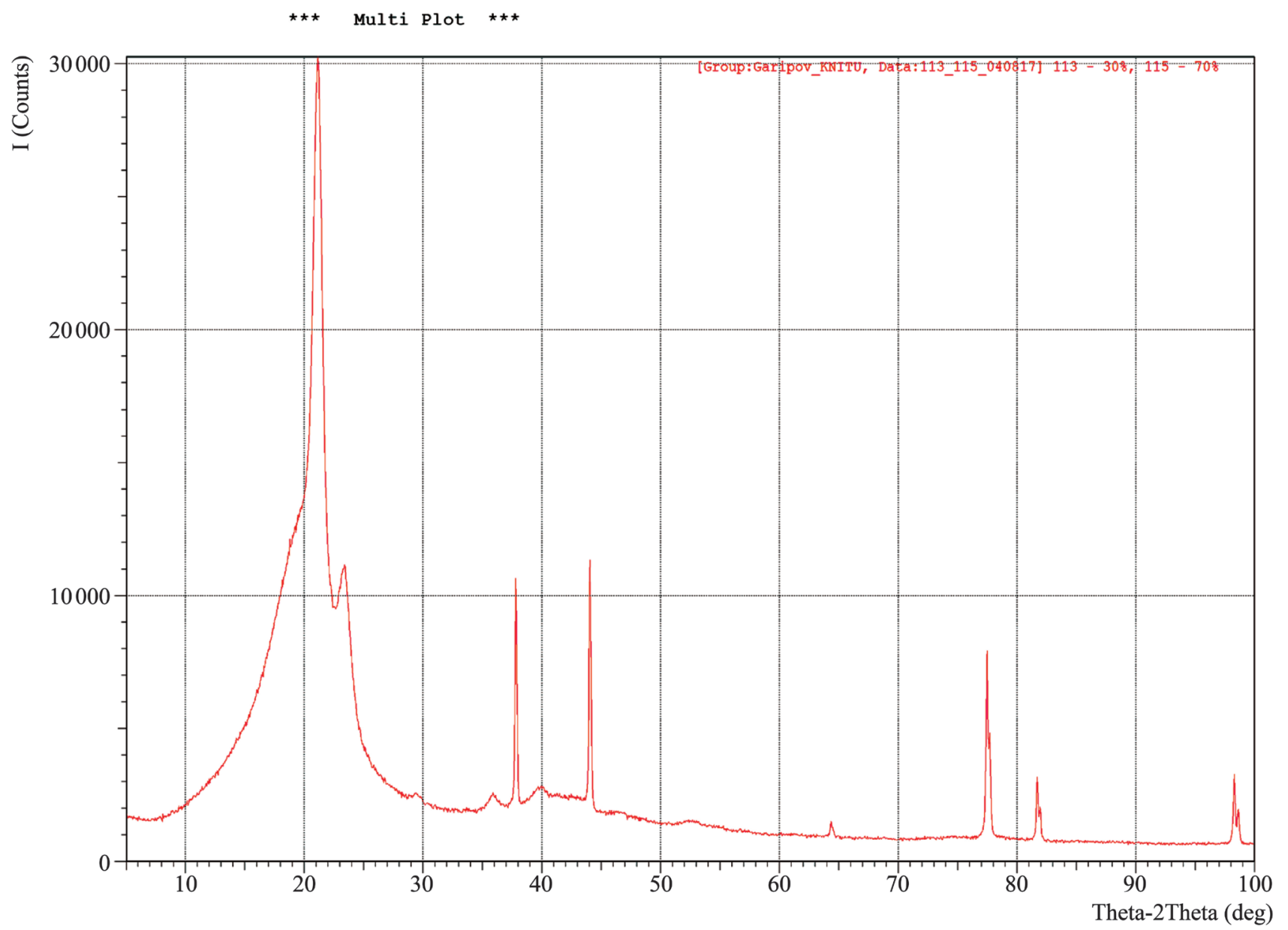

Рис. 3. Дифрактограмма смеси СЭВА-113 (30 \%) - СЭВА-115 (70 \%) в программе TOPAS 

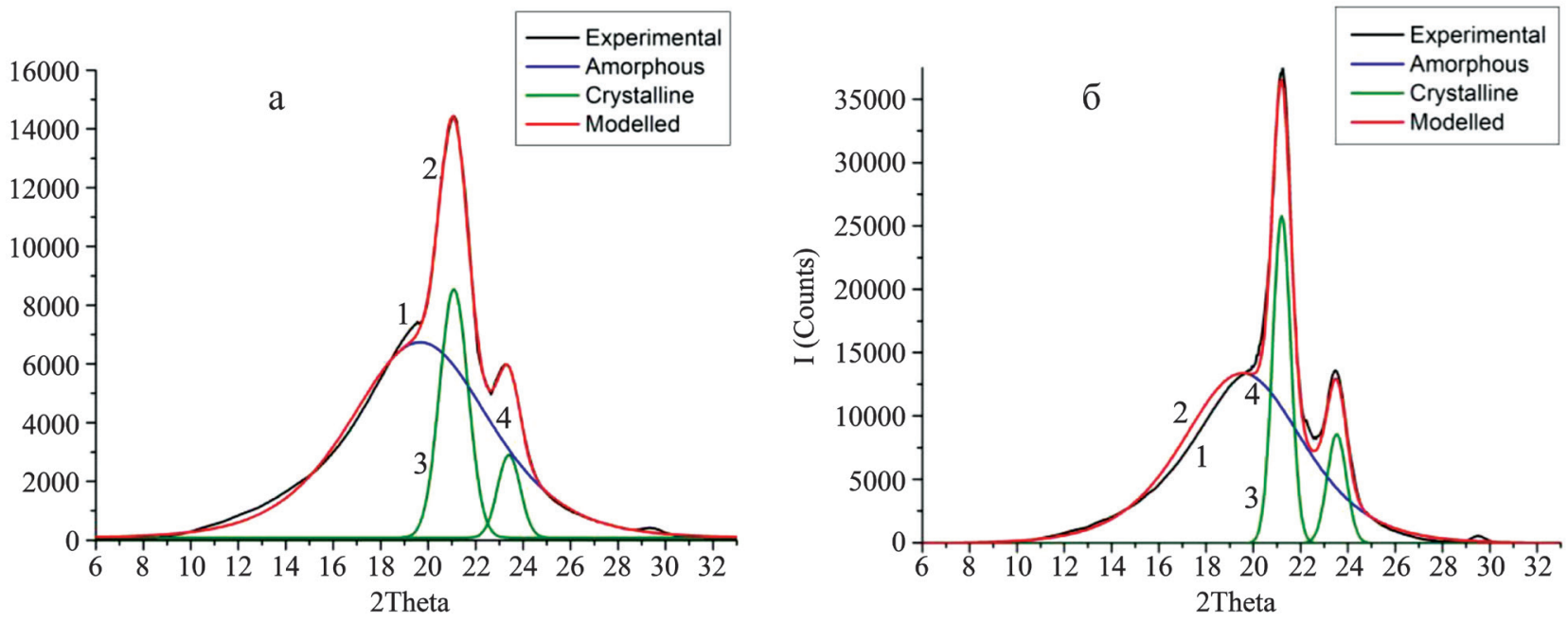

Рис. 4. Дифрактограммы смесей СЭВА-113 (30 \%)- СЭВА-115 (70 \%) - (a), ПЭВД-153 (50 \%) - СЭВА-118 (50 \%) - (б) в программе OriginPro

Черным ивветом (1) изображень экспериментальнье данные после сглаживания и вычитания фона и $K_{\alpha}$-линии; красным (2) - модельная дифрактограмма (сумма кривых синего и зеленого ияветов);

зеленым (3) - кристаллические пики, аппроксимированные гауссовыми функциями; синим (4) - аморфное гало, аппроксимированное ассиметричной двойной сигмондальной функцей
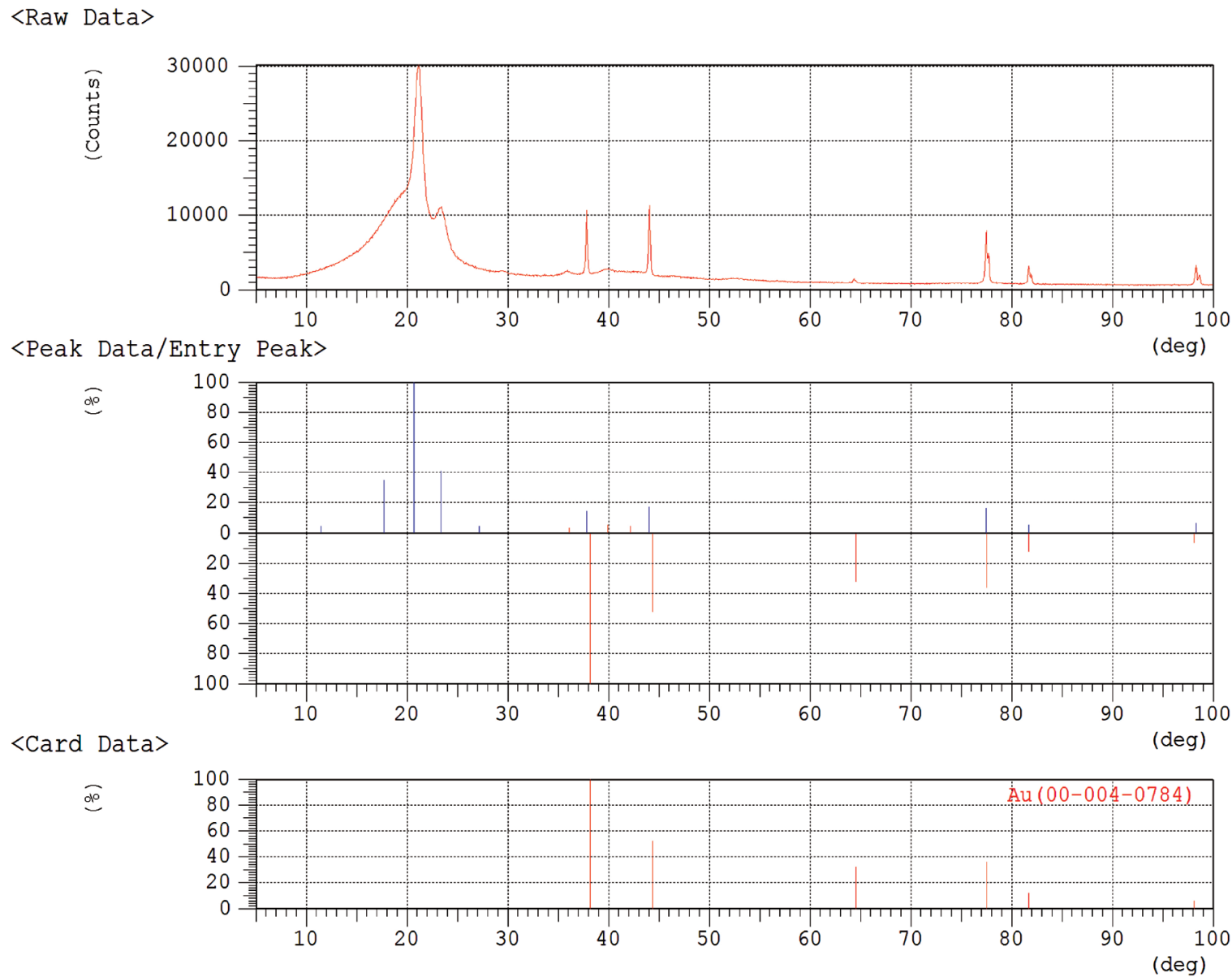

Рис. 5. Идентификация фаз смеси СЭВА-113 (30 \%) - СЭВА-115 (70 \%)

Верхний график - дифрактограмма исследуемого образия; нижний - дифракционные пики Аи из базы данных ICDD; иентральный - сравнение дифракционных пиков исследуемого образиа с базой данныхх 


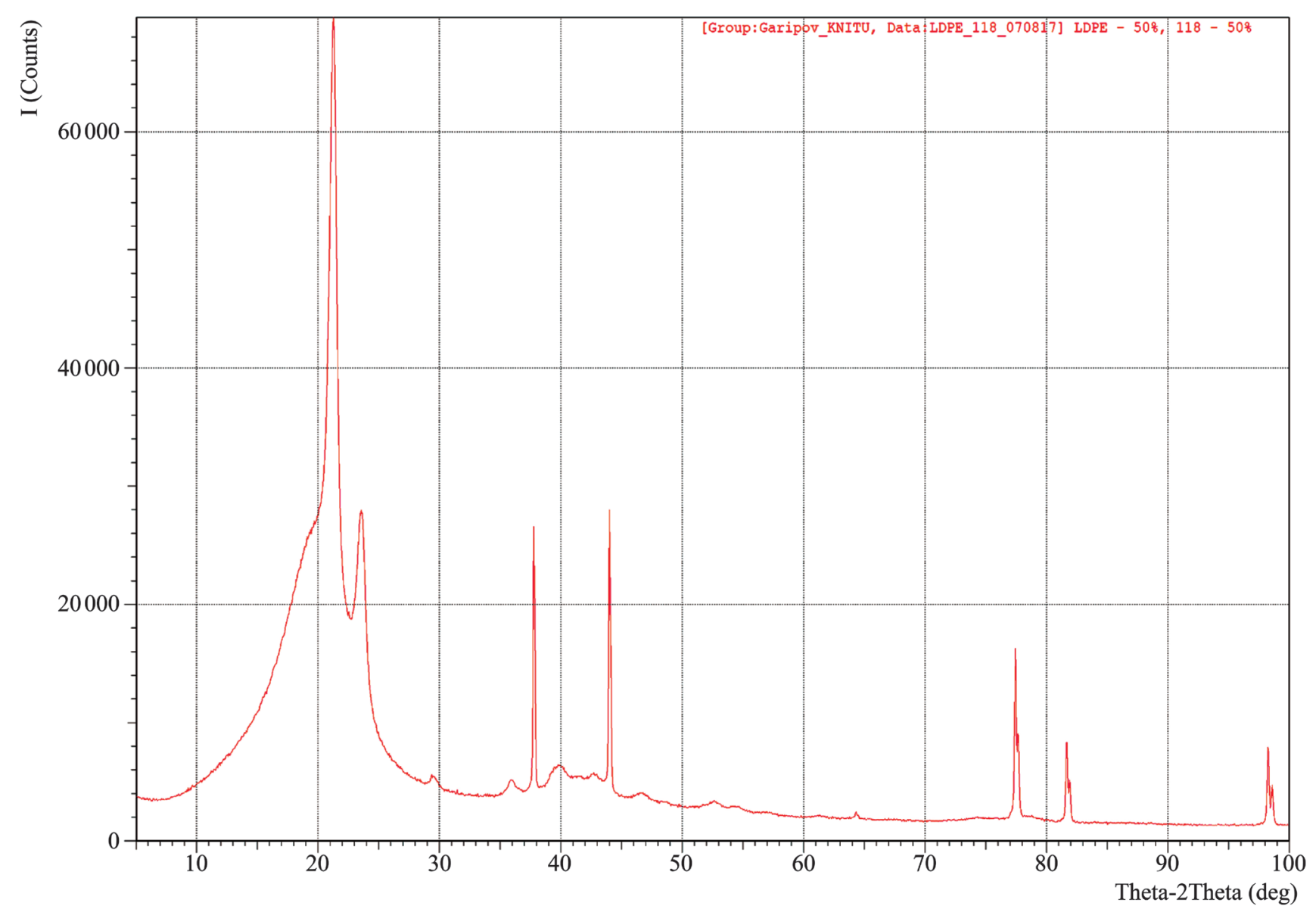

Рис. 6. Дифрактограмма смеси ПЭВД-153 (50 \%) - СЭВА-118 (50 \%) в программе TOPAS

танное в пакете OriginPro 8 по методике Аггарвала и Тилля [11]. В данной методике, степень кристалличности $a_{k}$ рассчитывается по формуле:

$$
a_{k}=\frac{I_{k}}{I_{k}+I_{a}} \cdot 100 \%
$$

где $I_{k}-$ интегральная интенсивность кристаллической фазы полимера, $I_{a}$ - интегральная интенсивность аморфного гало.

В образцах помимо аморфного гало и кристаллической фазы полимеров наблюдаются пики благородных металлов - Ag или $\mathrm{Au}$, поэтому также приведены результаты поиска по базе данных ICDD PDF-4. Наличие в образцах третьей фазы приводит к завышенным значениям степени кристалличности при расчете в программе TOPAS.

Для смесей СЭВА-113 - СЭВА-115 программа TOPAS дает следующее значение кристалличности $a_{k}=34 \%$, а расчет в пакете OriginPro показал следующий результат: $a_{k}=24 \%$.

На рисунках 5 и 7 показано, что пять дифракционных пиков смесей СЭВА-113 (30 \%) - СЭВА-
115 (70 \%) и ПЭВД-153 (50 \%) - СЭВА-118 (50 \%) совпадают по положениям и интенсивностям с пиками как с $\mathrm{Au}$, так и с $\mathrm{Ag}$.

Для смесей ПЭВД-153-СЭВА-118 программа TOPAS дает следующее значение кристалличности $a_{k}=36 \%$, а расчет в пакете OriginPro показал следующий результат $a_{k}=28 \%$.

Представленные исследования подтверждают повышение степени кристалличности смесей полученных при смешении по методу SEDS.

Повышение структурной упорядоченности должно, несомненно, привести к росту деформационно-прочностных свойств, полученных смесей. Для доказательства высказанного предположения были проведены физико-механические испытания изучаемых смесей. Результаты показаны в таблице 2 и на рисунке 8.

При анализе данных таблицы 2 можно сделать вывод о том, что для всех исследуемых смесей физико-механические показатели композиций, полученных смешением по методу SEDS, превышают показатели смесей, полученных смешением в расплаве. Особенно следует отметить композиции СЭВА-113(30 \%) - СЭВА-115 (70 \%) и СЭВА- 
$<$ Raw Data $>$

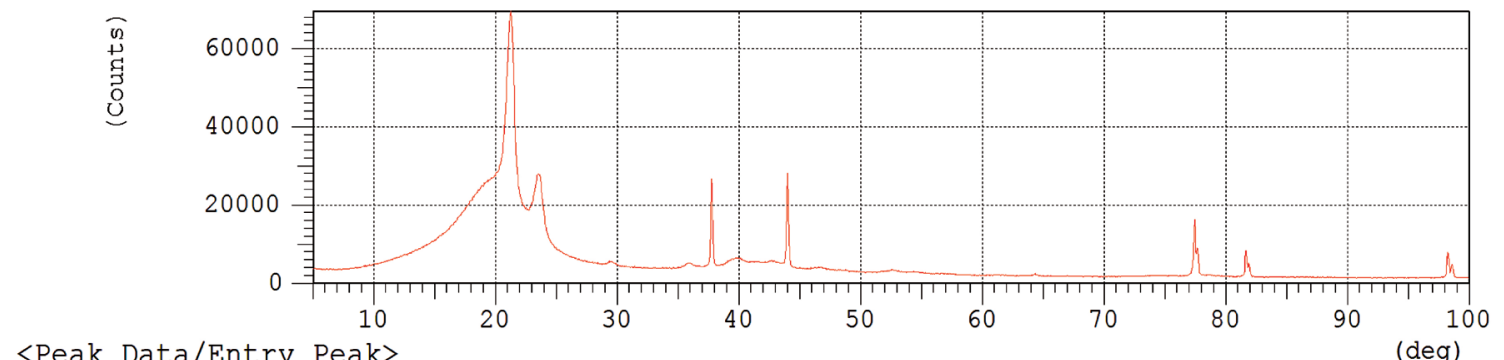

<Peak Data/Entry Peak>

(deg)

dio

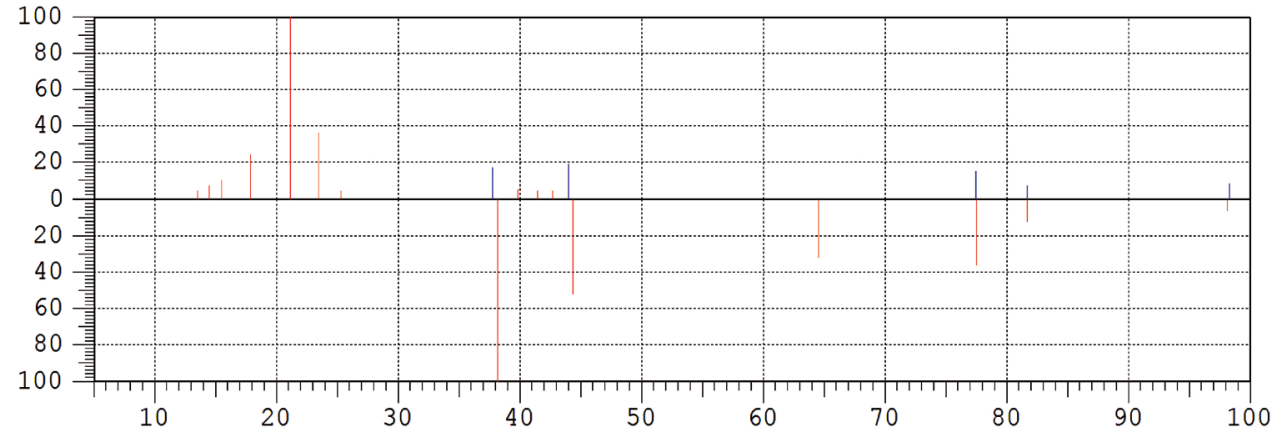

$<$ Card Data $>$

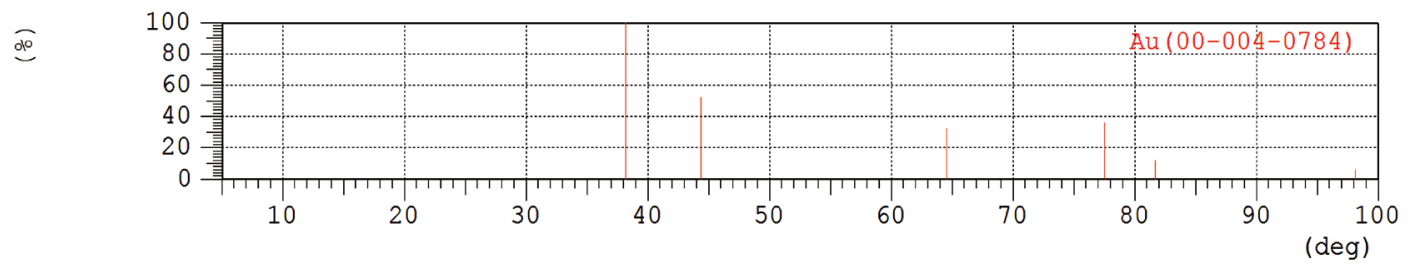

Рис. 7. Идентификация фаз смеси ПЭВД-153 (50 \%) - СЭВА-118 (50 \%)

Верхний график - дифрактограмма исследуемого образиа; нижнии - дифракиионнье пики Аи из базы данных ICDD; иентральный - сравнение дифракционных пиков исследуемого образияа с базой данных

Результаты физико-механических испытаний

\begin{tabular}{|c|c|c|c|c|c|c|c|}
\hline \multirow[b]{2}{*}{$\begin{array}{l}\text { №, } \\
\text { II/II }\end{array}$} & \multirow[b]{2}{*}{3} & \multicolumn{3}{|c|}{ Смешение по методу SEDS } & \multicolumn{3}{|c|}{ Смешение в расплаве } \\
\hline & & 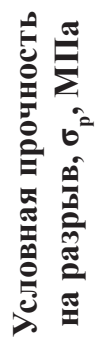 & 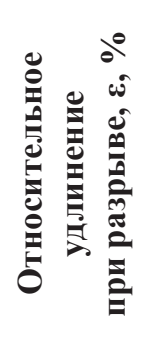 & 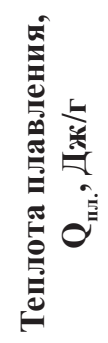 & 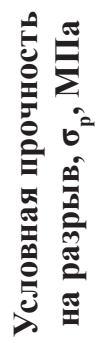 & 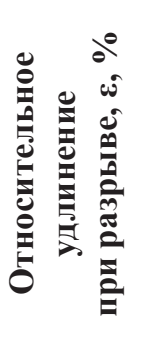 & 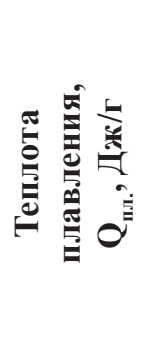 \\
\hline 1 & $\begin{array}{l}\text { СЭВА-113 }(30 \%) \\
\text { СЭВА-115 }(70 \%)\end{array}$ & 9 & 1430 & 29,77 & 7,35 & 660 & 11,94 \\
\hline 2 & $\begin{array}{l}\text { СЭВА-113 (70 \%) } \\
\text { СЭВА-115 (30 \%) }\end{array}$ & 13,5 & 730 & 28,98 & 11,51 & 727 & 25 \\
\hline 3 & $\begin{array}{l}\text { СЭВА-113 (50 \%) } \\
\text { СЭВА-118 (50 \%) }\end{array}$ & 9,3 & 720 & 19,93 & 7,7 & 550 & 16,25 \\
\hline 4 & $\begin{array}{l}\text { ПЭВД-153 (50 \%) } \\
\text { СЭВА-118 (50 \%) }\end{array}$ & 7,81 & 485 & 43,75 & 5,7 & 239 & 24,72 \\
\hline
\end{tabular}



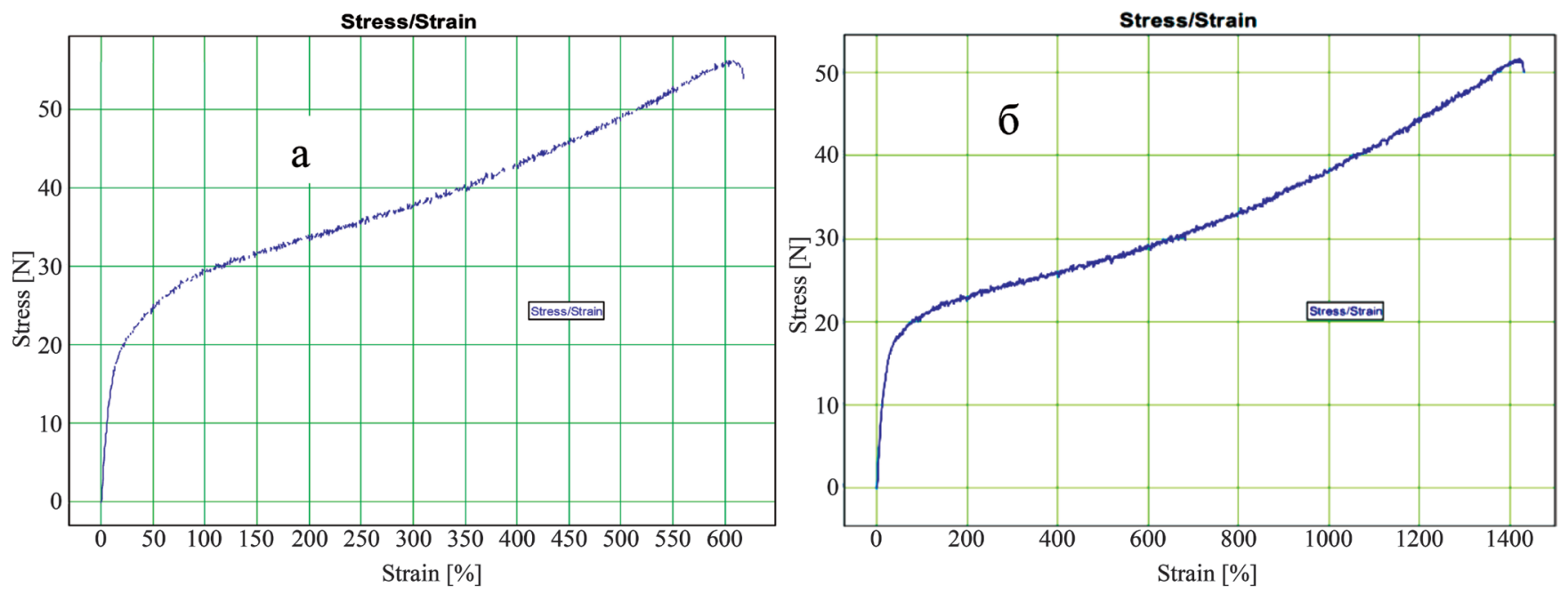

Рис. 8. Диаграмма испытаний прочности на разрыв смеси СЭВА113 (30 \%) - СЭВА115 (70 \%):

а) - смешение в расплаве, б) - смешение по методу SEDS

118 (50 \%) - ПЭВД-153(50 \%), где относительное удлинение возрастает более чем в 2 раза, а прочность при разрыве на $30 \%$.

Работа поддержана Российским научным фондом, проект № 19-73-10029.

\section{Лumepamypa}

1. Швари О., Эбелинг Ф.-В., Фурт Б. Переработка пластмасс. Под общей редакцией А.Д. Паниматченко. СПБ. «Профессия». 2005. 320 с.

2. Akkapeddi M.K. Commercial Polymer Blends, Polymer Blends Handbook, 0.1007/ 978-94-007-6064-6_22. 2014. C. 1733-1883.

3. Тагер А.А. Физиохимия полимеров. 3- изд., М. «Химия». 1978, $544 \mathrm{C}$.

4. Kemmere M.F., Meyer T. (Eds.) Supercritical Carbon Dioxide in Polymer Reaction Engineering. WILEYVCH VerlagGmbH. 2005. 1131 P.
5. Гумеров Ф.М., Сабирзянов А.Н., Гумерова Г.И. Суби сверхкритические флюиды в процессах переработки полимеров. Казань. Изд. «ФЭН». 2000, 328 С.; 2-ое изд. 2007, 336 C.

6. Kazarian S.G. Polymer Science, Ser. C. 2000. V. 42. № 1. P. 78-101.

7. Kiran E. J. of Supercritical Fluids. 2016. V. 110. P. 126-153.

8. Stoyanov O.V., Sechko E.V., Khuzakhanov R.M., Zaikov G.E. Molecular Crystals and Liquid Crystals. 2012. V. 556. P. 135-157.

9. Хузаханов Р.М., Сечко Е.В., Стоянов О.В. Адгезионные свойства бинарный смесей некоторых этиленовых сополимеров». Клеи. Герметики.Технологии. 2011. № 12. C. 17-20.

10. Khabriev I.Sh., Patrusheva M.N., Khairutdinov V.F., Khuzakhanov R.M., Gumerov F.M., Garipov R.M. Russian J. of Physical Chemistry B. 2018. V. 12. №8. P. 1229-1239.

11. Aggarwal S.L. and Tilley G.P. J. Polym. Sci. 1955. V. 18. P. 17-26. DOI: 10.1002/pol.1955.120188702. 